\title{
A CONCEPÇÃo DE CURRÍCULO NOS CURSOS SUPERIORES DE TECNOLOGIA ${ }^{1}$
}

\author{
The curriculum conception in Superior Technology Courses \\ NOGUEIRA, Antonio Wherbty Ribeiro² \\ MORAES, Ana Cristina de ${ }^{3}$ \\ XEREZ, Antônia Solange Pinheiro ${ }^{4}$
}

\begin{abstract}
Resumo
Este trabalho integra os estudos relacionados às concepções de currículo às da Educação Profissional e Tecnológica de nível superior materializados nos cursos de tecnologia. $O$ estudo justifica-se pela crescente oferta dos cursos de graduação tecnológica no âmbito nacional e de seus programas curriculares voltados para a formação de trabalhadores especializados em nível superior, identificados como "tecnólogos". O texto objetiva analisar as concepções curriculares que fundamentam a educação superior tecnológica na atualidade. A partir de uma abordagem qualitativa de pesquisa baseada na revisão bibliográfica, a construção deste texto alicerça-se em trabalhos já consolidados de autores que debatem as questões curriculares e a Educação Profissional e Tecnológica, bem como nos dispositivos legais que orientam e regulam a oferta destes cursos. Evidencia-se que o currículo dedicado à formação de tecnólogos privilegia os saberes tecnológicos e práticos, selecionados a partir da identidade ou perfil profissional exigido pelos postos de trabalho e no poder do mercado na definição dos propósitos que esses cursos assumem.
\end{abstract}

Palavras-chave: Currículo. Cursos Superiores de Tecnologia. Sociedade de mercado.

\section{ABstract}

This work integrates the studies related to the conceptions of curriculum to those of technological professional education of higher level materialized in the technology courses. The study is justified by the growing offer of technological undergraduate courses at the national level and of their curricular programs aimed at training specialized workers at higher level, identified as "technologists". The text aims to analyze the curricular conceptions that base technological higher education today. Through the qualitative research approach, the construction of this text is based on already consolidated works of authors who debate curricular issues and technological professional education, as well as in the legal provisions that guide and regulate the offer of these courses. It is evident that the curriculum dedicated to the training of technologists, favors technological and practical knowledge, selected based on the

\footnotetext{
${ }^{1}$ Este texto é parte da pesquisa realizada para a escrita da dissertação de mestrado sobre a Formação de Professores para atuação nos Cursos Superiores de Tecnologia no âmbito do Mestrado Acadêmico Intercampi em Educação e Ensino (MAIE) da Universidade Estadual do Ceará (UECE). As reflexões contidas neste trabalho não foram apresentadas ou publicadas em encontros ou eventos científicos. Para o desenvolvimento deste trabalho não houve apoio financeiro de órgãos de financiamento ou fomento.

${ }^{2}$ Especialista em Gestão Educacional e Práticas Pedagógicas pela Faculdade Única de Ipatinga. Graduado em História pelo Instituto Superior de Educação lbituruna, em Letras - Espanhol (UFC) e em Pedagogia pelo Centro Universitário UNISEB COC. Pedagogo na Faculdade de Tecnologia do Centro de Ensino Tecnológico CENTEC - Sertão Central. E-mail: antonio.wherberty@aluno.uece.br.

${ }^{3}$ Pós-doutora em Educação (UFC). Doutora em Educação pela Universidade de Campinas (UNICAMP-SP). Mestra em Educação pela Universidade Federal do Ceará (UFC). Especialista em Metodologia do Ensino de Artes pela Universidade Estadual do Ceará (UECE). Graduada em Arte-educação pela UniGrande e em Serviço Social pela Universidade Estadual do Ceará (UECE). Professora Adjunta da Universidade Estadual do Ceará (UECE). E-mail: cris.moraes@uece.br.

${ }^{4}$ Pós-doutora em Educação pela Universidade Federal do Ceará (UFC). Doutora em Educação pela Universidade Nove de Julho (UNINOVE-SP). Professora Adjunta da Universidade Estadual do Ceará (UECE), no Centro de Educação (CED). E-mail: antonia.xerez@uece.br.
} 
identity or professional profile required by jobs and the power of the market in defining the purposes that these courses assume.

Keywords: Curriculum. Higher Technology Courses. Market Society.

\section{INTRODUÇÃO}

Nas últimas cinco décadas no Brasil a Educação Profissional e Tecnológica (EPT) tem ganhado espaço no campo dos estudos educacionais por ser concebida como uma proposta de escolarização que alinha formação e trabalho, demandas urgentes e definidoras dos rumos de muitos jovens no país. A expansão dessa modalidade de ensino se dá num contexto de consolidação do pensamento capitalista em sua fase neoliberal que, alinhado às necessidades do mercado a partir da reestruturação produtiva e da mundialização do capital, se apropria das demandas sociais e atribui à educação a reponsabilidade por melhor qualificar os cidadãos-trabalhadoresconsumidores a partir de um ensino profissionalizante.

As especificidades da Educação Profissional e Tecnológica compreendem não apenas sua explícita relação com o mercado de trabalho, mas encontram-se também na intersecção entre este e o campo educacional. Convém destacar que a estreita relação entre o trabalho e a instrução ocorre desde a divisão da sociedade em classes (PONCE, 2010), passando por diferentes transformações na medida que o modo de produção de bens e riquezas passou a exigir da sociabilidade mudanças em seus processos formativos: das sociedades escravistas, passando pelo feudalismo, até a ascensão da burguesia ao poder político e econômico, a educação, em sentido stricto, conforme define Lukács (2015), manteve sua vocação como complexo responsável pela reprodução social.

Este quadro tende a se reproduzir conforme a vontade da classe dominante e seus interesses. Partindo da tese de Mészáros (2015) sobre o encontro do sistema capitalista com os limites sistêmicos de seu metabolismo social, classificado pelo autor como uma crise estrutural, assumimos o pressuposto de que o grande capital, afim para administrar seus desequilíbrios econômicos e suas consequências, aponta a educação como estratégia de superação de problemas como o desemprego e a pobreza, ressaltando, entre outros aspectos, a questão da qualificação profissional dos sujeitos como definidora de seu sucesso ou fracasso social. Desta feita, estrutura-se para a classe trabalhadora um ensino profissionalizante, radicalizado pela sua integração à educação básica e ao ensino superior.

Nesse contexto, os chamados Cursos Superiores de Tecnologia (CST), vêm se expandindo ${ }^{5}$ em grande medida como possibilidade de uma formação profissional especializada em nível superior, capaz de posicionar os filhos da classe trabalhadora em postos de trabalho "privilegiados" mediante cursos breves, de baixo custo, com formação específica para atuação nos setores produtivos da sociedade de mercado.

De acordo com o Censo da Educação Superior de 2007, os cursos tecnológicos já registravam um crescimento contínuo com a abertura de 700 novos cursos, chegando a um total de 3.702 cursos no âmbito nacional naquele ano (INEP, 2007). Dez anos depois,

\footnotetext{
5 À exemplo do Estado do Ceará, que de acordo com o portal E-MEC do Ministério de Educação (2020) possui 1.295 cursos superiores de tecnologia em atividade, nos mais diversos eixos tecnológicos. Em 2015, cinco anos atrás, esse número correspondia a 504 cursos.
} 
os Cursos Superiores de Tecnologia já registram um crescimento de $89 \%$ no número de cursos ofertados para população, tanto em instituições privadas como públicas, como ilustra o quadro a seguir.

Tabela 1- Evolução do número de cursos de graduação tecnológica no Brasil entre os anos de 2007 e 2017

\begin{tabular}{|l|l|l|}
\hline Ano & Total de cursos & Taxa de crescimento \\
\hline 2007 & 3.702 & $89 \%$ \\
\hline 2017 & 7.005 & \\
\hline
\end{tabular}

Fonte: Elaborada com base nos dados do Censo da Educação Superior de 2007 e 2017.

No período entre 2008 e 2018, o número de ingressantes nos cursos tecnológicos registrou o maior crescimento em termos percentuais, chegando a $102,9 \%$. No ano de 2019, a graduação tecnológica já concentrava 22,6\% do número de ingressos no ensino superior, ficando à frente dos cursos de licenciatura que acumularam 20,1\% desses (INEP, 2020).

O crescimento vertiginoso dos Cursos Superiores de Tecnologia nos últimos anos despertou o interesse de diversos pesquisadores da área educacional por se tratar de um curso com características específicas, distintas dos demais cursos de nível superior e dos cursos técnicos de nível médio, o que colaborou para que alguns autores os classificassem como cursos "intermediários" (BRANDÃO, 2013) e "não-universitários" (LIMA FILHO, 2003).

Na mesma linha, Santos e Xerez (2016) entendem que esses cursos possuem uma estreita relação com as necessidades do capital e são propagados para a população menos favorecida como a possibilidade de acesso ao Ensino Superior, através de cursos "aligeirados", "fragmentados", "flexíveis" e "praticista". Nesse sentido, os autores esclarecem que tais cursos são "estruturados para atender aos diversos setores da economia, e devem abranger áreas especializadas, articulando teoria e prática" (SANTOS; XEREZ, 2016, p. 604).

Trazendo o objeto para a esfera educacional, propomos a problematização dos Cursos Superiores de Tecnologia, ou cursos de Educação Profissional e Tecnológica de Graduação (BRASIL, 2021) a partir do referencial pedagógico das questões curriculares. Para isso, dialogando com Arroyo (2013), partimos do entendimento do currículo como um núcleo estruturante do complexo educativo, cercado e normatizado pelas relações de poder, isto é, politizado e constantemente ressignificado por aqueles que assumem os postos de decisão. Nessa direção, elencamos o seguinte questionamento: considerando os desdobramentos da sociedade de mercado capitalista sobre a educação, qual a concepção de currículo que fundamenta os Cursos Superiores de Tecnológica?

Diante desse cenário, este estudo, inserido na totalidade do contexto social do capitalismo em crise, busca analisar a concepção de currículo que fundamenta os Cursos Superiores de Tecnologia (CST). Para tanto, adotamos uma abordagem qualitativa de pesquisa, de natureza teórica, bibliográfica e documental, tendo como fio condutor os referenciais teóricos de Silva (1999; 2010), Sacristán (2013), Brandão (2013), entre outros; e os documentos oficiais que definem as atuais diretrizes curriculares para a Educação Profissional e Tecnológica no Brasil. 


\section{CuRRÍculo: SABER, IDENTIDADE E PODER}

A tarefa a que se propõe este estudo exige uma primeira aproximação de alguns paradigmas sobre o currículo. Tema carregado de certa polissemia, o currículo assume um papel como protagonista e definidor de muitas das questões que giram em torno dos processos educacionais. Etimologicamente, a palavra currículum se refere a um conjunto de honras acumuladas durante o percurso de vida de uma pessoa. É a partir dessa ideia que atualmente dois caminhos são apresentados para este verbete: o curriculum vitae como toda bagagem profissional de vida do sujeito e seus êxitos; e o currículo como instrumento de construção da carreira estudantil de um jovem, com seus conteúdos, organização e competências (SACRISTÁN, 2013).

No senso comum, a partir desta última definição, o currículo é concebido como um "plano de estudos" na qual as instituições de ensino deveriam alicerçar suas práticas, determinando que conteúdos os professores deveriam ensinar e os alunos deveriam aprender (SACRISTÁN, 2013, p. 19). Trata-se, nesta perspectiva, de uma seleção organizada dos conteúdos reguladores da prática didática que se desenvolve durante a escolaridade, responsável por organizar os segmentos e fragmentos dos conteúdos que o compõem.

O currículo é um modelo de ordenação que articula diferentes ações isoladas, sem a qual essas ficariam justapostas e desordenadas, fragmentando a aprendizagem. Tal função organizadora do currículo é vista como unificadora, mas que, se analisada mais a fundo, pode criar um paradoxo ligado ao fato de que esse mesmo currículo articulador impõe fronteiras que delimitam seus componentes, ao passo que modela e limita a autonomia dos professores.

Segundo Sacristán (2013), o currículo é concebido como um instrumento regulador dos conteúdos e das práticas educativas, ou seja, "[...] ele se comporta como um instrumento que tem a capacidade de estruturar a escolarização, a vida nos centros educacionais e as práticas pedagógicas" (SACRISTÁN, 2013, p. 20), já que determina regras, normas e uma ordem que são determinantes para o cotidiano escolar.

Para Silva (1999, p. 15), a centralidade das diferentes teorias curriculares é permeada pela questão de qual conhecimento deve ser ensinado. Segundo o autor, "A pergunta 'o que' (...) nos revela que as teorias do currículo estão envolvidas, explícita ou implicitamente, em desenvolver critérios de seleção que justifiquem a resposta que darão àquela questão". Nessa perspectiva, o currículo passa a ser fruto de uma seleção de conhecimentos a partir de um universo maior de diferentes saberes que poderão compor esse currículo tais como: saberes culturais, estéticos, éticos, históricos, políticos, tecnológicos, etc.

Assumindo a percepção dos dois autores, podemos considerar o currículo como um instrumento com o potencial de controlar uma série de aspectos ligados ao processo de formação humana, muito além de um mero compêndio de conteúdos a serem ensinados, o que lhe confere no campo político-ideológico um valor ainda maior. Os espaços e o tempo pedagógico, a formação dos professores, a organização da escola, as diretrizes, as ofertas de componentes curriculares, normas e guias curriculares, os livros didáticos e toda uma indústria cultural ligada a educação escolar partem daquilo que determinam os currículos. Tido como um "elemento estruturante" (ARROYO, 2013), o currículo determina não apenas a objetividade dos processos educativos, mas também a subjetividade dos sujeitos que a partir deles são formados. Em outras palavras, tanto o 
modelo de sociedade como a subjetividade dos indivíduos que nela vivem podem assumir os valores, princípios e saberes que o currículo preconiza, o que lhe dá status de um documento produtor de identidades. Desse modo, a questão do "que ensinar?", é precedida de outra questão fundamental: "o que eles ou elas devem ser?" ou "o que eles ou elas devem se tornar?" (SILVA, 1999, p. 15). Aqui encontramos uma visão do currículo sob um viés identitário, ou seja, capaz de determinar quem os sujeitos de uma determinada sociabilidade devem ser:

\begin{abstract}
Qual é o tipo de ser humano desejável para um determinado tipo de sociedade? Será uma pessoa racional e ilustrada do ideal humanista de educação? Será a pessoa otimizadora e competitiva dos atuais modelos neoliberais de educação? Será a pessoa ajustada aos ideais de cidadania do moderno estado-nação? Será a pessoa desconfiada e crítica dos arranjos sociais existentes preconizada nas teorias educacionais críticas? A cada um desses "modelos" de ser humano corresponderá um tipo de conhecimento, um tipo de currículo (SILVA, 1999, p. 15).
\end{abstract}

Surge desta concepção um dado importante à nossa incursão: pensar o currículo de modo óbvio e simplista, isto é, como um mero conjunto de conteúdos a serem ensinados, desconsidera todo seu potencial formador de sujeitos dentro de uma teia complexa de relações sociais contraditórias, como a instituída pelo capital. Convém considerar, alinhados ao pensamento de Carvalho (2014, p. 60), que o currículo, "[...] sempre remeterá a modelos mais amplos, a visões de mundo, a percepções acerca dos processos de reprodução social e cultural vigentes". Desse modo, o currículo compreende um território contestado pela ideologia dominante, ávida por controlar o complexo responsável pela reprodução social, ou seja, a educação. Durante o século XVIII, por exemplo, ao definir que os trabalhadores precisavam de alguma instrução devido aos avanços tecnológicos da Revolução Industrial, os capitalistas trataram de determinar não só o que esses trabalhadores deveriam aprender (ler, escrever e operar a maquinária), mas quem estes seriam no contexto fabril (sujeitos adaptados, conformados, dedicados à produção e moralmente controlados).

O fato de o currículo ser um instrumento regulador dos conhecimentos relevantes à escola e constituidor de identidades coloca-o sobre a égide das questões de poder. Para Silva (1999, p. 15), "selecionar" ou "privilegiar" saberes é uma operação de poder na medida em que, ao fazê-lo privilegia-se, entre múltiplas possibilidades, uma identidade ou subjetividade como sendo ideal. Nesse sentido, as teorizações curriculares encontram-se para além do campo puramente epistemológico, na medida em que estão envolvidas também no campo social, político e ideológico.

$\mathrm{Na}$ esteira das ideias acima expostas, evidenciamos que quando o Estado assume a condução do complexo educativo e nele constitui para as camadas populares um modelo de ensino profissionalizante pautado nas demandas do mercado de trabalho, integrando-o à educação básica e ao ensino superior, toma-se um posicionamento alinhado à ideologia capitalista de formação e qualificação dos sujeitos a serem convertidos como força de trabalho. Este processo demanda, portanto, uma concepção curricular capaz de organizar a estrutura das instituições educativas, regulamentar a prática pedagógica e definir quem serão os indivíduos egressos dos cursos profissionalizantes.

Antes de analisarmos os Cursos Superiores de Tecnologia (CST) e suas diretrizes curriculares, importa considerarmos esta tematização a partir da totalidade do contexto social na qual se inserem, tomando como ponto de partida a seguinte questão: Quais os 
desdobramentos da crise estrutural em que se encontra o capital sobre a educação e o currículo?

\section{REestruturação PROdutiva, EdUCAÇÃo E CURRículo}

Partindo do referencial teórico da crítica marxista, a tese de Mészáros (2015, p. 103) nos apresenta evidências de um esgotamento dos padrões de enriquecimento e de expansão do modo de produção capitalista, levando esse sistema a encontrar-se com seus limites absolutos, inaugurando numa nova fase denominada pelo autor de "crise estrutural do capital". Esse fenômeno, iniciado na década de 1970, passou a exigir do grande capital um processo de reestruturação produtiva, inserindo novas tecnologias e estabelecendo novos padrões de produção e consumo, cujos impactos compreendem diferentes esferas sociais, a fim de que seja restabelecida a lucratividade.

No complexo do trabalho, essa reestruturação produtiva compreende o fim do modelo de produção taylorista/fordista, substituído pelo modo de acumulação flexível, também conhecido como toyotismo. Além disso, verifica-se, conforme Castioni (2010), a ampliação do papel do Estado na promoção da industrialização nos países periféricos como o Brasil. No campo político, ocorre o avanço do ideário neoliberal pela implantação do Estado mínimo, de privatização dos serviços públicos, de corte nos gastos e de responsabilização do ente governamental e dos indivíduos pelo atraso e fracasso social, eximindo as estruturas contraditórias do capital de qualquer culpa sobre os problemas sociais como a pobreza e o desemprego.

Nessa direção, o processo de reestruturação produtiva estabelece novos imperativos ao sistema educacional. De acordo com Maia Filho, Mendes Segundo e Rabelo (2016), o papel atribuído à educação no cenário de crise do capital estaria vinculado à instrução técnica, política e ideológica dos trabalhadores diante das novas e urgentes necessidades sociorreprodutivas do mercado. Nesses termos, caberia ao complexo educativo formar e qualificar cada sujeito como um "otimizador do mercado" (consumidor, entusiasta do desenvolvimento e da "nova" ordem mundial) e "produtor de mercadorias" (aquele que compõe a grande massa refém da exploração pelo trabalho e/ou do desemprego) (SILVA, 2010, p. 08).

Nesse cenário, a escolarização é ressignificada a ponto de ser assumida como principal solução para problemas estruturais como o desemprego, a fome e a miséria, pois estes seriam frutos da falta de qualificação profissional dos sujeitos e da incapacidade do Estado em ofertar uma educação alinhada aos avanços tecnológicos e aos novos padrões de produção do mercado. Assim sendo, inferimos que o modelo de ensino profissionalizante articulada à educação básica e ao ensino superior, proposto pelo capital em sua fase neoliberal, por meio dos organismos multilaterais como o Banco Mundial (BM) e a Organização das Nações Unidas para a Educação, a Ciência e a Cultura (UNESCO), busca adaptar e adequar a formação dos jovens filhos da classe trabalhadora ao ambiente de trabalho e à lógica mercadológica hodierna, objetivando o que Silva (2010, p. 08) classificou como um processo de "naturalização desse cenário".

Logo, sendo parte estruturante do complexo educativo, o currículo assume determinada centralidade no processo de construção das reformas educacionais no contexto da reestruturação produtiva do capital, com posição estratégica em torno dos diferentes significados sociais e políticos da educação. Em síntese, compreendemos, acompanhando Silva (2010, p. 12), que o currículo não é um campo neutro e imparcial, 
pois uma vez inserido na tessitura social das relações de classe "fabrica os objetos de que fala: saberes, competências, sucesso, fracasso, (...) estabelece diferenças, constrói hierarquias, produz identidades".

Ciente do poder incorporado pelo currículo e do cenário onde este se insere, apresentaremos a seguir os Cursos Superiores de Tecnologia (CST) como um tipo específico de educação profissional que emerge da estreita relação entre os setores produtivos, o mercado de trabalho e a educação no contexto de crise estrutural do capital ora apresentado. Desta feita, passaremos a análise das diretrizes curriculares que orientam os cursos de Educação Profissional e Tecnológica, dentre os quais encontramse os CST.

\title{
Os Cursos Superiores de TeCNologia e suAS diREtrizes CURRICULARES
}

No esforço de revisitarmos a gênese constitutiva dos Cursos Superiores de Tecnologia (CST), nos aproximamos dos estudos de Brandão (2013, p. 308) que, partindo da década de 1960, evidencia uma pesquisa encomendada pela Organização dos Estados Americanos (OEA) e realizadas pelo Ministério da Educação e Cultura (MEC) em parceria com a Fundação Getúlio Vargas (FGV) com o objetivo de promover "[...] estudos sobre recursos humanos, atitude considerada indispensável ao planejamento econômico e social (BRANDÃO, 2013, p. 308)".

Essa pesquisa debruçou-se sobre a categoria profissional dos engenheiros de produção, considerados importantes para a época, uma vez que tal ofício estava alinhado à expansão da indústria nacional, sobretudo a automobilística. Este estudo serviu de base para um plano encabeçado pela Diretoria de Ensino Superior (DES) que previu a existência de duas categorias de engenheiros, classificadas de acordo com o tempo de duração dos cursos de formação:

\begin{abstract}
Um deles de cinco anos, obedecendo à duração e currículos já fixados pelo CFE, continuaria formando profissionais com as atribuições criadoras de pesquisa, de desenvolvimento e de elaboração de projetos. O outro, com duração de 3 anos, formaria o engenheiro de operação. Teria o primeiro, uma formação mais científica, enquanto o segundo apresentaria uma formação mais prática. (BRANDẨ, 2013, p. 308, itálico nosso).
\end{abstract}

Pareceres encaminhados pelo Conselho Federal de Educação (CFE) à DES respaldaram a abertura de um caminho legal para a criação de uma modalidade de cursos de curta duração distinta para engenheiros, denominados como engenharia de operação. Estes eram justificados pela exigência da indústria por profissionais mais especializados numa "[...] faixa menor de atividades, capaz de encaminhar soluções para os problemas práticos do dia a dia da produção, assumindo cargos de chefia e orientando na manutenção e na superintendência de operações" (PARECER CNE/CP 29, 2002, p. 5).

Diante desse cenário, sublinhamos que, desde sua origem, os CST nos revelam traços de uma dominação e exploração do capitalismo contemporâneo sobre a formação dos trabalhadores. Na esteira Castioni (2010, p. 60), fundamentado em Chauí (1981), percebemos como o capital mantém seu metabolismo de reprodução social pautado na expropriação do trabalho humano "sobrepondo à divisão de classes uma segunda divisão social que é a divisão entre os que sabem, e por isso, dirigem, e os que não sabem, por isso executam". Mais recentemente, percebemos que esta divisão permanece em outros termos, como: os competentes e os incompetentes. 
A partir da implantação desses cursos de caráter intermediário e alinhados aos interesses do capital estrangeiro ${ }^{6}$ evidenciamos, um novo capítulo do histórico dualismo educacional brasileiro com a divisão do Ensino Superior entre uma formação profissional prática e científica. Para Brandão (2013, p. 317) o objetivo desta nova política de educação superior era formar sujeitos capazes de "[...] reproduzir, operar e manter a tecnologia e os processos industriais que o Brasil importava de outros países, inclusive dos Estados Unidos da América do Norte".

A criação de uma modalidade de Ensino Superior que atendesse aos anseios do mercado representa o fenômeno da importância dada pelos setores econômicos à educação, como abordado na sessão anterior. Rodrigues (1998, p. 135) reafirma este aspecto em seu estudo quando assevera que os empresários industriais brasileiros da Confederação Nacional da Industria (CNI) "sempre estiveram presentes no campo da luta hegemônica-pedagógica, buscando criar os homens à sua imagem e necessidade", o que nos mostra como o complexo educativo e o currículo compreendem um território de disputas sociais, políticas e ideológicas pelo controle da formação humana.

Os cursos de engenharia de operação acabaram por ser extintos ainda durante a década de 1970, mas seu modelo dual de estruturação permaneceu imbricado nas políticas de educação profissional de nível superior. Durante seu processo de expansão, os CST sinalizavam para as mesmas características presentes nos de engenharia de operação, ou seja, promoviam uma "[...] formação de nível intermediário entre o nível médio e o superior, assim como uma formação voltada predominantemente para a prática, e não para a pesquisa e investigação; e, por isso não exigindo uma formação de base científica sólida" (BRANDÃO, 2013, p. 325).

Já na década de 1990, o processo de "cefetização" das Escolas Técnicas Federais permitiu àquelas instituições a organização e o planejamento de cursos de nível superior tecnológico. Para Santos e Xerez (2016), entre outros pesquisadores, este referencial é tido como um marco inicial da política educacional voltada para os Cursos Superiores de Tecnologia (CST), determinando as principais características encontradas nas diretrizes mais recentes para a Educação Profissional.

Com a homologação da Lei de Diretrizes de Bases da Educação Nacional (LDB) no 9.394/1996 e suas alterações posteriores, ocorre a materialização do interesse do Estado-burguês-capitalista de estruturar uma Educação Profissional e Tecnológica integrada "[...] aos diferentes níveis e modalidades de educação e às dimensões do trabalho, da ciência e da tecnologia" (BRASIL, 1996), por meio de cursos de formação inicial e continuada, técnicos de nível médio e de graduação e pós-graduação tecnológica. Assim, coube ao Conselho Nacional de Educação (CNE), a partir da LDB de 1996, definir as diretrizes curriculares para tais cursos, sendo a Resolução CNE/CP no 01, de 05 de janeiro de 2021 a de mais recente redação.

Conforme nos indica a Resolução CNE/CP ํㅜ 01 de 2021, em seu artigo 2º, além de integrada às diferentes modalidades e níveis de ensino, a Educação Profissional e Tecnológica (EPT) organiza-se por meio de eixos tecnológicos, "em consonância com a estrutura sócio-ocupacional do trabalho e as exigências da formação profissional nos diferentes níveis de desenvolvimento". Nesses termos, a EPT parte de princípios

\footnotetext{
${ }^{6} \mathrm{~A}$ Fundação Ford, ligada à indústria automobilística, fomentou e estimulou junto ao governo brasileiro a criação desses de cursos de curta duração em nível superior no âmbito das Escolas Técnicas Federais (BRANDÃO, 2013).
} 
norteadores que seguem sua natureza histórica de articulação com o setor produtivo, cujo objetivo maior é o preparo dos sujeitos para o "exercício das profissões operacionais, técnicas e tecnológicas, na perspectiva da inserção laboral dos estudantes" (BRASIL, 2021, artigos $2^{\circ}$ e $3^{\circ}$ ).

Para a norma vigente, o princípio educativo que rege a EPT é o trabalho, sendo este "[...] a base para a organização curricular, visando à construção de competências profissionais, em seus objetivos, conteúdos e estratégias de ensino e aprendizagem, na perspectiva de sua integração com a ciência, a cultura e a tecnologia" (BRASIL, 2021, artigo 3o, inciso IV). No entanto, devemos considerar nesta análise o atual sentido do trabalho na sociedade capitalista, isto é, o trabalho como emprego, como produtor de mercadoria, como meio de exploração das potencialidades humanas pelo capital, como produtor de desigualdade e contradições. Percebemos que tais aspectos não figuram como temas a serem discutidos na formação profissional dos sujeitos, onde privilegia-se o desenvolvimento das competências e habilidades exigidas para a produção, em detrimento de uma formação integral, crítica e reflexiva.

Ao definir que os cursos de Educação Profissional e Tecnológica permanecerão em constante "articulação com o desenvolvimento socioeconômico e os arranjos produtivos locais", a Resolução CNE/CP no 02 de 2021, assume como identidade de seus estudantes um perfil profissional vinculado à "natureza do trabalho", visando contribuir para a "empregabilidade de seus egressos" (BRASIL, 2021, artigo $3^{\circ}$ ). Neste sentido, nos aproximamos das discussões de Moura (2013), quando este entende a empregabilidade como sendo uma falácia imposta às camadas mais populares ávidas por formação e emprego. O autor nos esclarece que na lógica do capital não há emprego para todos, o que condicionam os indivíduos a uma constante busca por formação e especialização para trabalhar, inserindo em suas subjetividades a competitividade e o viés mercadológico próprio das relações sociais capitalistas.

Tratando de modo específico os cursos de Educação Profissional e Tecnológica de Graduação, ou Cursos Superiores de Tecnologia (CST), objeto deste estudo, sublinhamos dentre seus objetivos o desenvolvimento de "[...] competências profissionais tecnológicas, gerais e específicas, para a produção de bens e serviços e a gestão estratégica de processos", bem como a garantia de uma "[...] identidade do perfil profissional de conclusão de curso e da respectiva organização curricular" (BRASIL, 2021, artigo 28ㅇ). Notamos que a vertente de nível superior do ensino profissionalizante, como não poderia ser diferente, acompanha as diretrizes curriculares gerais para a EPT, assumindo como eixo norteador de sua organização o que os setores produtivos e o mercado demandam: sujeitos competentes para a produção, gerenciamento e reprodução das estruturas produtivas da sociedade do capital.

Conforme a resolução aqui analisada, na estruturação dos CST devem ser "[...] organizados por unidades curriculares, etapas ou módulos que correspondam as qualificações profissionais identificáveis no mundo do trabalho" (BRASIL, 2021, artigo $29^{\circ}$, itálico nosso). Essas unidades curriculares, por sua vez, devem ser estruturadas "[...] para o desenvolvimento das competências profissionais" (BRASIL, 2021, artigo 30).

Desta análise, compreendemos que as diretrizes curriculares para a Educação Profissional e Tecnológica, em especial as que tratam dos Cursos Superiores de Tecnologia (CST), assumem o currículo como um instrumento definidor das identidades profissionais de seus estudantes, estruturadas a partir do conjunto de demandas e exigências impostas pelo mercado e pelos setores produtivos do sistema capitalista. 
Essa identidade estrutura-se por meio de eixos tecnológicos divididos em unidade curriculares organizadas de acordo um conjunto de competências e habilidade específicas para a natureza do trabalhado.

Nessa perspectiva, notamos que um alinhamento das diretrizes curriculares aqui analisadas com a categoria competência. Esta é analisada por Remi Castioni nos debates contemporâneos como noção absoluta, cujo alcance tem se expandido para além da formação profissional". Para o autor "[...] a competência é tida como noção porque tem referência estrita ao indivíduo, abstraído das relações sociais em uma sociedade configurada por relações de trocas mercantis capitalistas" (CASTIONI, 2010, p.15). Desse modo, a adoção da ideologia da competência como eixo estruturante dos currículos da EPT torna-se conveniente à reprodução social do sistema capitalista, uma vez que o indivíduo é considerado isoladamente, alheio às estruturas que lhe exploram e dissimulam. Em síntese, o ser humano em sua formação para e pelo trabalho é reduzido a um homo economicus.

\section{Considerações FinaIS}

As relações estabelecidas nos parágrafos acima nos situaram histórica e politicamente quanto à gênese e ao desenvolvimento dos chamados cursos de Educação Profissional e Tecnológica de Graduação, ou Cursos Superiores de Tecnologia (CST). Mediante o diálogo com os autores e autoras citadas e a análise dos dispositivos legais que regulamentam esses cursos, percebemos que a categoria do trabalho, em seu sentido histórico de emprego e sob a égide das contraditórias relações capitalistas, é assumida como princípio norteador das diretrizes curriculares dos CST.

A articulação entre o tipo de educação dedicada à classe trabalhadora e as competências e habilidade exigidas pelo mercado ditam o modelo de Ensino Superior profissionalizante materializado nos CST. Desde sua concepção na década de 1960, tais cursos servem ao propósito vinculado aos interesses do capital pela formação de mão de obra cada vez mais qualificada, baseada nos imperativos da reestruturação produtiva do capital em crise sobre o sistema educacional brasileiro.

A revisão teórica dos referenciais pedagógicos que tratam das questões curriculares nos revelaram que o currículo, para além do entendimento comum de um documento definidor de conteúdos, é um instrumento estruturante e regulamentador das práticas pedagógicas envolvidas nos processos de formação humana. Nesses termos, o currículo assume um status de poder, dado a sua capacidade de definir não apenas o que será ensinado, mas quem serão os indivíduos que a partir dele são formados. Assim, inseridos na perspectiva crítica de currículos, compreendemos este como um mecanismo capaz de estabelecer diferentes identidades.

Considerando as asserções de Lukács (2015) de que no processo de constituição da sociabilidade a educação é um complexo responsável pela reprodução das estruturas sociais presentes, percebemos que em meio a organização ditada pelo capitalismo, a oferta de uma Educação Profissional e Tecnológica integrada à educação básica e superior, dedicada à classe trabalhadora, serve em grande medida aos interesses da classe dominante na manutenção do status quo e na administração da crise estrutural.

\footnotetext{
${ }^{7}$ Vide as mais recentes reformas curriculares empreendidas no Brasil como a da Base Nacional Comum Curricular (BNCC) que adotam a pedagogia da competência como eixo estruturante.
} 
Sob os discursos da empregabilidade e da promoção do acesso dos jovens filhos das camadas populares, o Estado promove a expansão de um tipo de ensino profissionalizante capaz de formar indivíduos alinhados aos interesses do mercado.

Desta feita, as diretrizes curriculares que orientam tais cursos permanecem vinculadas à logica da formação para e pelo trabalho, a partir de uma pedagogia das competências convenientemente organizada por meio de eixos tecnológicos e unidades curriculares articuladas às habilidades, saberes e atitudes exigidas pelo mercado. A natureza do trabalho é quem define quem serão os egressos dos CST, isto é, o trabalho é quem define a identidade profissional dos sujeitos. Percebemos uma formação unilateral, voltada para as ocupações profissionais e para o futuro laboral dos sujeitos, alheio a qualquer dimensão cultural, estética, filosófica, humanista de formação.

Evidenciamos, assim, que o currículo para a formação de tecnólogos está embasado nos saberes tecnológicos e práticos, na identidade ou perfil profissional exigido pelos postos de trabalho e no poder do mercado na definição dos propósitos que os CST abraçam. Em síntese, esses cursos, na perspectiva da constituição de seus currículos, se aproximam, em certa medida, dos primórdios das teorias curriculares preconizadas nos Estados Unidos por Bobbit (1918) em The curriculum. Naquela conjuntura, a fábrica era o modelo institucional da concepção de currículo. Hoje, esse modelo compreende todo o setor produtivo de bens e serviços, para o qual os estudantes dos CST são qualificados levando em consideração as demandas impostas pelos meios de produção.

Surge, nesse cenário, a problemática da superficialidade funcional presente na formação dada pela Educação Profissional e Tecnológica orientada pelas atuais diretrizes curriculares e ditadas pelo capital. Tais diretrizes valorizam a produtividade e a competitividade em detrimento do devido tratamento pedagógico dos fundamentos científicos e histórico-sociais que estão por traz dos saberes tecnológicos, da tecnologia e do trabalho em seu sentido ontológico.

Por fim, entendemos que Cursos Superiores de Tecnologia (CST) compreendem uma possibilidade de educação superior germinada no seio da sociedade de mercado em pleno avanço e crescimento, o que amplia em igual escala a necessidade de estudos e análises que objetivem, por exemplo, relacionar sua expansão à qualidade do ensino ofertado. No hemisfério oposto à atual lógica hegemônica da educação unilateral capitalista apresentada neste trabalho encontra-se uma concepção de formação humana omnilateral que considera o ser humano em sua totalidade, isto é, como seres do trabalho, do conhecimento, da tecnologia e da cultura.

\section{REFERÊNCIAS}

ARROYO, Miguel G. Currículo, território em disputa. Editora Vozes Limitada, 2013.

BRASIL. Ministério da Educação. Lei no 9.394, de 20 de dezembro de 1996. Estabelece as diretrizes e bases da educação nacional. Brasília, DF: 20 de dezembro de 1996. Disponível em: http://www.planalto.gov.br/ccivil_03/leis/L9394.htm. Acesso em: 27 mai. 2020.

BRASIL. Ministérios da educação/Conselho Nacional de Educação. Parecer CNE/CES 436 de 05 de abril de 2001. Dispõe sobre os Cursos Superiores de Tecnologia - Formação de Tecnólogos. Diário Oficial [da República Federativa do Brasil], Brasília, DF, 06 abr. 2001, seção 1E, p. 67. Disponível em: http://portal.mec.gov.br/cne/arquivos/pdt/CES0436.pdf. Acessado em: 22 abr. 2020

BRASIL. Ministério da Educação. Conselho Nacional de Educação. Resolução CNE/CP no 01, de 05 de janeiro de 2021. Define as Diretrizes Curriculares Nacionais Gerais para a Educação Profissional e Tecnológica. Diário Oficial da União, Brasília, 6 de janeiro de 2021, Seção 1, pp. 19-23. 
http://portal.mec.gov.br/index.php?option=com_docman\&view=download\&alias=167931-rcp00121\&category_slug=janeiro-2021-pdf\&ltemid=30192. Acesso em 23 ago. 2021.

BRASIL. Ministério de Educação. Cadastro Nacional de Cursos e Instituições de Educação Superior Cadastro e-MEC. Disponível em: https://emec.mec.gov.br/. Acessado em 23 ago. 2021.

BRASIL. Ministério da Educação. Censo escolar da Educação superior 2007. Brasília, DF: Inep/Deaes, 2020.

BRASIL. Ministério da Educação. Censo escolar da Educação superior 2017. Brasília, DF: Inep/Deaes, 2020.

BRANDÃO, Marisa. Cursos Superiores de Tecnologia: uma formação intermediária. in: MOURA, Dante Henrique (Org.). Produção de Conhecimento, políticas públicas e formação em Educação Profissional. Campinas, São Paulo: Mercado de Letras, 2013, p. 307-343.

CARVALHO, Celso do Prado Ferraz de. 0 currículo oficial paulista no contexto das teorias crítica e pós-crítica da educação. Dialogia, n. 20, p. 99-120, 2014.

CASTIONI, Remi. Educação no mundo do trabalho: qualificação e competência. São Paulo: Francis, 2010.

INSTITUTO NACIONAL DE ESTUDOS E PESQUISAS EDUCACIONAIS ANÍSIO TEIXEIRA. Sinopse Estatística da Educação Superior 2019. Brasília: Inep, 2020. Disponível em: http://portal.inep.gov.br/basica-censo-escolar-sinopse-sinopse. Acesso em: 23 ago. 2021.

LIMA FILHO, Domingos Leite. A descentralização da escola. Impactos da reforma da educação profissional - período 1995-2002. Curitiba: Torre de Papel, 2003.

LUKÁCS, György. Para uma ontologia do ser social I. Boitempo editorial, 2015.

MAIA FILHO, Osterne Nonato; SEGUNDO, Maria das Dores Mendes; RABELO, Josefa Jackline. 0 problema do mundo do trabalho no atual contexto da crise estrutural do capital. Cadernos de Pesquisa, p. 28-41, 2016. Disponível em: http://www.periodicoseletronicos.ufma.br/index.php/cadernosdepesquisa/article/view/4627. Acesso em: 22 ago. 2021.

MÉSZÁROS, István. Para além do capital: rumo a uma teoria da transição. Boitempo Editorial, 2015.

MOURA, Dante Henrique. Mudanças na sociedade brasileira dos anos 2000 limitadas pela hegemonia do neoliberalismo: implicações para o trabalho e para a educação. in: MOURA, Dante Henrique (Org.). Produção de Conhecimento, políticas públicas e formação em Educação Profissional. Campinas, São Paulo: Mercado de Letras, 2013, p. 109-140.

PONCE, Aníbal. Educação e luta de classes. Tradução de José Severo de Camargo Pereira. 2010.

RODRIGUES, José. 0 moderno príncipe industrial: o pensamento pedagógico da Confederação Nacional da Industria. Campinas: Autores Associados (Coleção Educação Contemporânea), 1998.

SACRISTÁN, José Gimeno. O que significa currículo? In: SACRISTÁN, José Gimeno (Org.). Saberes e Incertezas sobre o currículo. Porto Alegre: Penso, 2013, p. 16-35.

SANTOS; José Deribaldo Gomes dos; XEREZ; Antonia Solange Pinheiro. Apontamentos sobre a expansão da graduação tecnológica no Brasil. Revista online de Política e Gestão Educacional, Araraquara, v.20, n.03, p. 600-622, 2016. Disponível em: <http://dx.doi.org/10.22633/rpge.v20.n3.9712>. ISSN: 1519-9029.

SILVA, Tomaz Tadeu. 0 currículo como fetiche: a poética e a política do texto curricular. Belo Horizonte: autêntica Editora, 2010.

SILVA, Tomaz Tadeu. Documentos de Identidade. Uma Introdução às teorias do currículo. Belo Horizonte, Autêntica, 1999.

Data da submissão: 15/06/2021

Data da aprovação: 24/08/2021 